Neue Gefahr durch

\section{Tuberkulose}

Tuberkulose (TB) ist selten in Deutschland, die Krankheit darf aber nicht unterschätzt werden, betont das Robert KochInstitut (RKI) im gerade erschienenen „Bericht zur Epidemiologie der Tuberkulose in Deutschland für 2014“. Probleme bereiten steigende Erkrankungszahlen, resistente TB-Erreger sowie ein hoher Anteil offener und damit infektiöser Lungentuberkulosen. Tuberkulose konzentriert sich zunehmend in Risikogruppen, so der Bericht. So traten von den 4488 Neuerkrankungen im Jahr 2014 fast zwei Drittel (62\%) bei Patienten mit Migrationshintergrund auf und damit in einer Gruppe, deren Zahl stark wächst.

\section{Keine Symptome bei Meningitis?}

Die klassische Meningitis-Symptomkonstellation - Fieber, Nackensteife und Bewusstseinseintrübung - kann besonders bei Kindern und Jugendlichen fehlen. Außerdem sind die Symptome einer bakteriellen Meningitis bei Kindern und Jugendlichen offenbar geschlechtsspezfisch: Jungen haben eher Kopfschmerzen, Mädchen eher Krampfanfälle. Darauf haben Pädiater aus Schweden hingewiesen. Um Symptome bei Krankheitsbeginn zu eruieren, analysierten sie Daten von unter 18-Jährigen aus einem Register des Landes der Jahre 1986 bis 2013. Angaben von insgesamt 103 Heranwachsenden mit akuter bakterieller Meningitis lagen vor.

www.aerztezeitung.de

\section{Hepatitis C aufs} Abstellgleis bringen

Deutschland ohne Hepatitis C - Fiktion oder Wahrheit? Wenn man sich die Ausheilungsraten von über $95 \%$ mit den neuen interferonfreien Behandlungsmethoden vor Augen führt, scheint dieses Ziel gar nicht mehr so unrealistisch zu sein. Doch Experten warnen: Bessere Therapien alleine reichen nicht aus, um die Erkrankung zurückzudrängen; höhere Behandlungsraten sind unumgänglich. Vertiefen Sie dieses und weitere spannende Themen in unserem Schwerpunkt.

Claudia Daniels Redakteurin

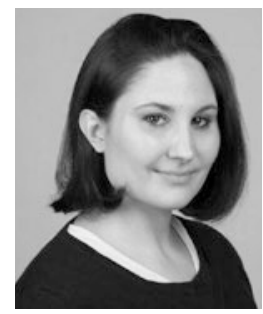

\title{
Immunsystem durch Sport ankurbeln
}

Forscher haben dank „Big Data“, d.h. mithilfe von 20 Datenbanken, neue Moleküle identifiziert, die für die Replikation des Grippe-Virus eine wichtige Rolle spielen. Blockiert man diese Wirtsproteine, können sich Influenza-Viren weniger gut vermehren, heißt es in einer Mitteilung der Universität Zürich. Damit trägt die internationale Studie dazu bei, neue Therapien und Grippemedikamente zu entwickeln. In den letzten Jahren wurden Influenza AViren (IAV) entdeckt, die durch Mutationen gegen die verfügbaren Medikamente zur Grippebehandlung resistent sind. Um sich innerhalb von Atemwegszellen zu replizieren, sind Influenza-Viren auf Wirtsmoleküle angewiesen. Deshalb wurde in den letzten Jahren versucht, die für diesen Prozess wichtigen Wirtsmoleküle zu identifizieren und zu blockieren, um so das Virus zu stoppen. Dank der umfassenden Analyse der „OMICs“-Datenbanken konnten 20 bisher unerkannte Wirtsmoleküle entdeckt werden, die das Wachstum von Influenza-A-Viren fördern.

www.aerztezeitung.de,

Cell Host \& Microbe 2015; 18(6): 723-735

\section{Gehäuft Herzinfarkt und Schlaganfall nach Gürtelrose}

Ein Herpes zoster erhöht offenbar über mehrere Monate hinweg das Risiko für Herzinfarkt und Schlaganfall. In den ersten Wochen ist die Inzidenz sogar verdoppelt. Forscher fanden in einer US-Datenbank rund 43.000 Patienten mit einer Gürtelrose und einem Herzinfarkt sowie über 24.000 Versicherte mit Zoster und einem ersten ischämischen Schlaganfall. Im Median lagen Daten über fünf Jahre nach der Zosterdiagnose vor, das Alter bei der Diagnose betrug im Mittel 80 Jahre.
Rund 2,5\% der Patienten hatten vor der Gürtelrose eine Zosterimpfung erhalten, etwa $6 \%$ danach. Tatsächlich zeigte sich unmittelbar nach Beginn der Gürtelrose eine erhöhte Schlaganfall- und Herzinfarktinzidenz. Diese war in der ersten Woche für Schlaganfall um das 2,4-fache und für Herzinfarkt um das 1,7-fache erhöht - verglichen mit der Inzidenz ein bis fünf Jahre nach der Diagnose.

Minassian Cet al. PLoS Med 2015;12(12): e1001919
In einer Studie über die Effekte von Sport auf das Immunsystem haben Forscher gezeigt, dass Sport eine entzündungshemmende Wirkung besitzt. Die Forscher konnten nachweisen, dass intensive, regelmäßige sportliche Betätigung zu einem Anstieg von entzündungshemmenden Immunzellen, den sogenannten regulatorischen T-Zellen führt, heißt es in der Mitteilung. Im Rahmen der Studie untersuchten sie Blutproben von jungen Eliteathleten - unter anderem auch der deutschen Hockey-Olympiamannschaft - und verglichen diese mit Proben von jungen und gesunden, aber untrainierten Probanden. Die Analyse der Daten habe ergeben, dass die Frequenz der regulatorischen T-Zellen in Abhängigkeit von der körperlichen Fitness der Probanden zunahm. Diese Ergebnisse legten den Schluss nahe, dass körperliche Aktivität durch eine Steigerung regulatorischer T-Zellen entzündungshemmende Effekte erziele.

www.aerztezeitung.de

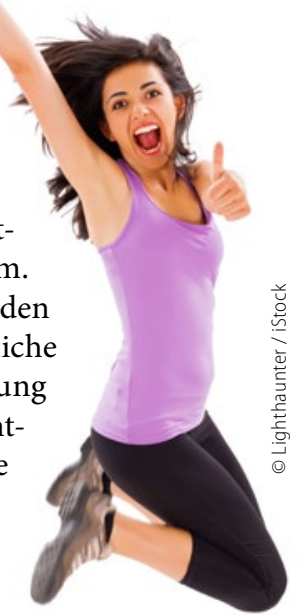

